\title{
14-3-3 $\varepsilon$ is a nuclear matrix protein, and its altered expression and localization are associated with curcumin-induced apoptosis of MG-63 cells
}

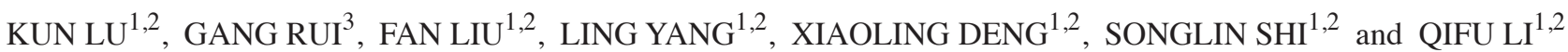 \\ ${ }^{1}$ Department of Basic Medicine, Medical College of Xiamen University; \\ ${ }^{2}$ Cancer Research Center of Xiamen University, Xiamen, Fujian 361102; ${ }^{3}$ Department of Orthopedics, \\ The First Affiliated Hospital of Xiamen University, Xiamen, Fujian 361003, P.R. China
}

Received August 5, 2016; Accepted September 13, 2017

DOI: $10.3892 / \mathrm{ol} .2017 .7283$

\begin{abstract}
The 14-3-3 protein family may regulates protein interaction, transportation and cellular localization. The regulatory role of $14-3-3 \varepsilon$ is influenced by its altered localization. In the present study, human osteosarcoma MG-63 cells were treated with curcumin to induce apoptosis. Subsequently, the altered expression and localization of 14-3-3e and its co-localization with other apoptosis-associated proteins during apoptosis was investigated. Analysis of nuclear matrix proteins (NMPs), using two-dimensional gel electrophoresis with matrix-assisted laser-desorption/ionization time-of-flight mass spectrometry, revealed that $14-3-3 \varepsilon$ existed on the nuclear matrix of MG-63 cells, and its expression was decreased compared with that in control cells following curcumin treatment. In addition, western blot analysis validated that the expression level of 14-3-3e was downregulated during curcumin-induced apoptosis of MG-63 cells compared with that in control cells. Using immunofluorescence labeling, it was observed that $14-3-3 \varepsilon$ was located on the nuclear matrix of MG-63 cells and the distribution of $14-3-3 \varepsilon$ on the nuclear matrix was decreased following treatment with curcumin, compared with that in control cells. Double immunofluorescence staining and laser-scanning confocal microscopy demonstrated that $14-3-3 \varepsilon$ was co-localized with B-cell lymphoma-2 (Bcl-2), Bcl-2-associated-X protein, p53 and c-FOS transcription factor in MG-63 cells. Furthermore, following treatment with curcumin, these co-localization regions were decreased. The results of the present study revealed that $14-3-3 \varepsilon$ is an NMP in MG-63 cells, and its altered expression and co-localization with apoptosis-associated proteins indicated
\end{abstract}

Correspondence to: Dr Qifu Li or Dr Songlin Shi, Department of Basic Medicine, Medical College of Xiamen University, South Xiangan Road, Xiamen, Fujian 361102, P.R. China

E-mail: chifulee@xmu.edu.cn

E-mail: shisonglin@xmu.edu.cn

Key words: 14-3-3e, nuclear matrix, human osteosarcoma cell, apoptosis, curcumin an important function of 14-3-3e in apoptosis of MG-63 cells. Additional studies are required to investigate the results of the present study.

\section{Introduction}

The 14-3-3 protein family are highly conserved soluble acidic proteins (1). There are 7 isoforms (including $\beta, \varepsilon, \eta, \gamma, \tau, \zeta$ and $\sigma$ ) in the 14-3-3 family, with molecular masses ranging between 28 and $33 \mathrm{kDa}(1)$. The 14-3-3 proteins may function as adaptor molecules or scaffolds of protein-protein interactions, or act as localization anchors, controlling the subcellular localization of proteins, or as enzyme activity regulators, increasing or suppressing their catalytic activity (2). As a member of the 14-3-3 protein family, $14-3-3 \varepsilon$ may integrate a number of signaling pathways by interacting with distinct proteins; therefore, $14-3-3 \varepsilon$ serves functions in the regulation of the cell cycle $(3,4)$ and apoptosis $(5-8)$. Previously, 14-3-3e has been reported to bind with heat shock factor 1 (HSF1) through the extracellular signal regulated kinase/glycogen synthase kinase 3/14-3-3e pathway, thus suppressing HSF1 activity during cellular proliferation (9). Zhong et al (6) demonstrated that inhibiting the interaction of $14-3-3 \varepsilon$ with chloride intracellular channel protein 4 enhanced autophagy and contributed to mitochondrial and ER stress-induced apoptosis under starvation conditions. In addition, $14-3-3 \varepsilon$ has an association with the occurrence and development of a number of types of tumor; for example, the expression of $14-3-3 \varepsilon$ has been identified to be downregulated in gastric cancer (10) and pediatric astrocytoma (11), whereas it is upregulated in hepatocellular carcinoma $(12,13)$, renal cancer $(14)$ and breast cancer (15).

Previous studies have revealed that certain isoforms of 14-3-3 protein family may inhibit cell apoptosis (16-20). In the present study, it was demonstrated that $14-3-3 \varepsilon$ was a differentially expressed nuclear matrix component in MG-63 cells during apoptosis. The nuclear matrix is composed of the nuclear lamina, the nucleolar remnants and an internal nuclear mesh of fibers of an unknown constitution that it is possible to visualize by electron microscopy (21). Alteration of nuclear matrix protein composition was demonstrated to be involved 
in the apoptotic process (22). The present study revealed that $14-3-3 \varepsilon$ was an altered nuclear matrix protein, suggesting that $14-3-3 \varepsilon$ may be an important regulator in curcumin induced apoptosis. However, the regulatory mechanism of $14-3-3 \varepsilon$ in cell carcinogenesis and apoptosis remains unknown. In the present study, further investigations were performed on the expression and localization of $14-3-3 \varepsilon$ and its co-localization with apoptosis-associated proteins in order to improve the current understanding of $14-3-3 \varepsilon$ function in the regulation of cellular carcinogenesis and apoptosis.

\section{Materials and methods}

Materials. Human osteosarcoma MG-63 cells were purchased from Xiangya Central Experiment Laboratory (Changsha, China). Curcumin standards were purchased from Fuzhou Min Jian Medicine Inspection Service (Fuzhou, China).

Cell culture and induction of apoptosis. Human osteosarcoma MG-63 cells were cultured in RPMI-1640 medium (Gibco; Thermo Fisher Scientific Inc., Waltham, MA, USA) containing $10 \%$ fetal bovine serum (Zheijiang Tianhang Biotechnology Co., Inc., Hangzhou, China), $100 \mathrm{U} / \mathrm{ml}$ penicillin and $100 \mathrm{U} / \mathrm{ml}$ streptomycin, at $37^{\circ} \mathrm{C}$ in a humidified atmosphere containing $5 \% \mathrm{CO}_{2}$. Induction of apoptosis was performed following a method described previously (22). Cells in the exponential phase were digested with $0.25 \%$ trypsin (Xiamen Lulong Biotech Development Co., Inc., Xiamen, China) and transferred to new plates. After $24 \mathrm{~h}$, the medium was replaced with fresh RPMI-1640 medium with or without $7.5 \mu \mathrm{g} / \mathrm{ml}$ curcumin. Cells were incubated with curcumin at $37^{\circ} \mathrm{C}$ for 0-48 $\mathrm{h}$ and collected at the corresponding time.

Selective extraction of nuclear matrix proteins (NMPs). NMPs were extracted following a modified method described previously by Michishita et al (23). Selected cells were washed with PBS three times. Subsequently, cells were resuspended with cytoskeleton extraction buffer CSK100 [10 mM Pipes, $\mathrm{pH}$ 6.8, $300 \mathrm{mM}$ sucrose, $100 \mathrm{mM} \mathrm{NaCl}, 3 \mathrm{mM} \mathrm{MgCl}{ }_{2}, 1 \mathrm{mM}$ EGTA, $1 \mathrm{mM}$ phenylmethylsulfonyl fluoride (PMSF) and $0.5 \%$ Triton X-100] and incubated on ice for $10 \mathrm{~min}$. Lysates were centrifuged at $900 \mathrm{x}$ g for $5 \mathrm{~min}$ at $4^{\circ} \mathrm{C}$, and the resulting supernatant was discarded. The precipitate was washed with cytoskeleton extraction buffer CSK50 (10 mM Pipes, pH 6.8, $300 \mathrm{mM}$ sucrose, $50 \mathrm{mM} \mathrm{NaCl}, 3 \mathrm{mM} \mathrm{MgCl} \mathrm{m}_{2}, 1 \mathrm{mM}$ EGTA, $1 \mathrm{mM}$ PMSF and $0.5 \%$ Triton X-100) twice. CSK50 containing 400 U/ml DNase I (Sangon Biotech Co., Ltd., Shanghai, China) was added to the precipitate prior to incubation at room temperature for $30 \mathrm{~min}$. Subsequently, $1 \mathrm{M}(\mathrm{NH} 4)_{2} \mathrm{SO}_{4}$ was added dropwise to the tube to a final concentration of $0.25 \mathrm{M}$. After 15 min of incubation at room temperature, NMPs were obtained by centrifugation at $900 \mathrm{x}$ g for $5 \mathrm{~min}$ at $4^{\circ} \mathrm{C}$. NMPs were washed with CSK50 once. The supernatant was removed and the proteins were stored at $-80^{\circ} \mathrm{C}$ until use.

Two-dimensional (2D) gel electrophoresis and mass spectrometry analysis. NMPs were re-dissolved in 2D sample buffer which containing $7 \mathrm{M}$ urea, $2 \mathrm{M}$ Tthiourea, 4\% CHAPS, 40 mM Tris-base, $2 \%$ pharmalyte (pH 3-10), 40 mM DTT, $1 \mathrm{mM}$ PMSF, $1 \mathrm{mM}$ EDTA. The 2D PAGE process was performed following a previously described method (24). For first dimension separation, immobilized $\mathrm{pH}$ gradient (IPG) strips (11 cm, $\mathrm{pH} 4-7$ ) were used and a total of $350 \mu \mathrm{g}$ proteins were loaded, followed by isoelectric focusing electrophoresis according to the optimized procedure. IPG strips were rehydrated with the sample buffer containing $350 \mu \mathrm{g}$ protein, and were then subjected to isoelectric focusing (IEF) using an Ettan IPGphor 3 IEF System (GE Healthcare, Chicago, IL, USA). The focus procedure was as follows: Step 1, $100 \mathrm{~V}$ slow ramp for $30 \mathrm{~min}$; step 2, $200 \mathrm{~V}$ slow ramp for $30 \mathrm{~min}$; step 3, $500 \mathrm{~V}$ slow ramp for $30 \mathrm{~min}$; step $4,1,000 \mathrm{~V}$ rapid ramp for $1 \mathrm{~h}$; step 5, 8,000 V slow ramp for $4 \mathrm{~h}$; step 6, 8,000 V rapid ramp for $40,000 \mathrm{~V} / \mathrm{h}$; step 7 , a hold at $500 \mathrm{~V}$. Following IEF, IPG strips were equilibrated in $6 \mathrm{M}$ urea, $2 \%$ SDS, $50 \mathrm{mM}$ Tris-HCl, pH 8.8, 20\% v/v glycerol, and 2\% DTT for $15 \mathrm{~min}$ and then, for an additional $15 \mathrm{~min}$, placed in the same buffer but with DTT replaced by $2.5 \%$ iodoacetamide. The strips were then placed on $10 \%$ SDS-PAGE gels. Electrophoresis was performed at $10 \mathrm{~mA} / \mathrm{gel}$ at $4^{\circ} \mathrm{C}$ overnight, followed by silver staining as previously described (25).

Gels were scanning using the GE ImageScanner III (GE Healthcare) and analyzed using PDQuest 8.0 software (Bio-Rad Laboratories, Inc., Hercules, CA, USA). When spots were detected in PDQuest, the original gel image was filtered and smoothed to clarify the spots, then three-dimensional Gaussian spots were created from the clarified spots. Spot quantity was defined as the total intensity of a defined spot in a gel image. The formula for calculating the quantity of Gaussian spots in PDQuest was as follows: Spot quantity=spot height $\mathrm{x}$ $\pi \mathrm{x} \sigma \mathrm{x} x \sigma \mathrm{y}$. Spot height is the peak intensity of the Gaussian representation of the spot, measured in terms of optical density (OD). $\sigma x$ and $\sigma y$ are the standard deviation of the Gaussian distribution of the spot in the direction of the $\mathrm{x}$ - and $\mathrm{y}$-axis, respectively, measured in IU $(1 \mathrm{IU}=100 \mu \mathrm{M})$. Protein spots with a fold change $>2$ were defined as differential protein spots and subjected to matrix assisted laser desorption ionization-time of flight mass spectrometry (MALDI-TOF-MS) analysis.

Gel particles of differential protein spots were excised and subsequently destained with a solution containing 50\% acetonitrile and $50 \mathrm{mM}$ ammonium bicarbonate at room temperature several times, until the gel particles were colorless. The gel particles were dehydrated in $100 \%$ acetonitrile, followed with centrifugation under vacuum at $400 \mathrm{x}$ g for $30 \mathrm{~min}$ at $42^{\circ} \mathrm{C}$. Dehydrated particles were digested with trypsin (Promega Corporation, Madison, WI, USA) at $37^{\circ} \mathrm{C}$ for $16 \mathrm{~h}$. The peptide fragments were extracted using $50 \%$ acetonitrile containing $5 \%$ trifluoroacetic acid (TFA). Samples were then dehydrated by centrifugation under vacuum at $400 \mathrm{x}$ g for $30 \mathrm{~min}$ at $42^{\circ} \mathrm{C}$.

Extracted peptide fragments were dissolved in $1 \mu \mathrm{l}$ $0.1 \%$ TFA and then blended with an equal volume of a-cyano-4-hydroxycinnamic acid (Sigma-Aldrich; Merck KGaA, Darmstadt, Germany). Samples were then spotted on a target plate. Following air-drying at room temperature, samples were analyzed using MALDI-TOF-MS (Reflex III MALDI-TOF; Bruker Daltonics, Leipzig, Germany). A 337 nm nitrogen laser was used to irradiate and ionize the samples with the pulse width set at $3 \mathrm{~ns}$. The source 1 and source 2 accelerating voltage were set at 20 and $23 \mathrm{kV}$, respectively. The delay extraction time was 2,000 ns. The mass-to-charge ratios $(\mathrm{m} / \mathrm{z})$ were determined by the time of ions flying in the 


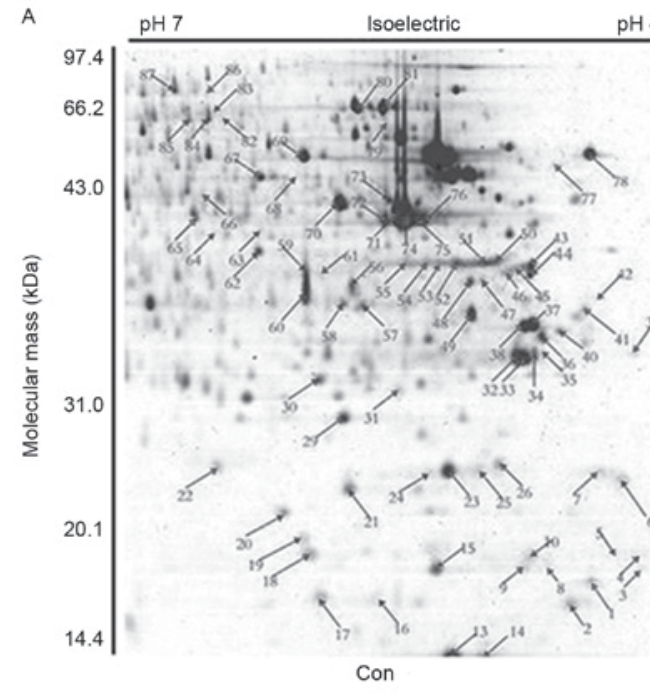

B

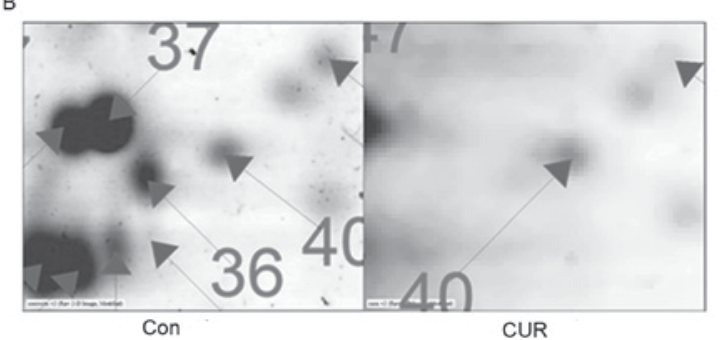

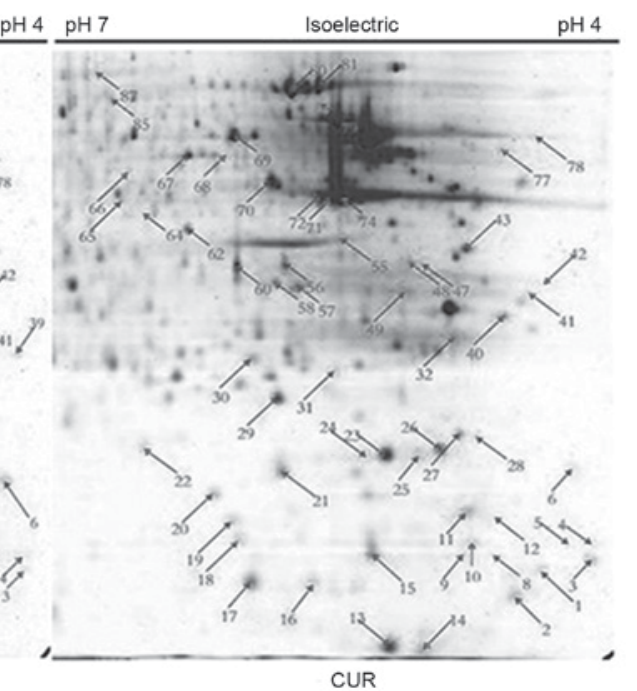

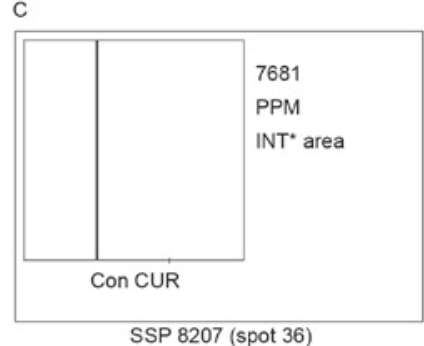

Figure 1. Two-dimensional gel electrophoresis of NMPs in MG-63 cells treated with or without curcumin. (A) Two-dimensional $11 \mathrm{~cm}, \mathrm{pH} 4-7 \mathrm{immobilized}$ $\mathrm{pH}$ gradient strips were used for isoelectric focusing. Protein spot 36 was identified as 14-3-3e. (B) Partial enlargement image of spot 36. (C) Quantification of spot 36 in Con and CUR; maximal value was 7,681 PPM. Using PDQuest software, spot quantity=spot height $\mathrm{x} \pi \mathrm{x} \sigma_{\mathrm{x}} \mathrm{x} \sigma_{\mathrm{y}}$ (INT area). PPM, parts per million; Con, control; CUR, curcumin-treated; INT, intensity. Normalization method, total quantity in valid spots.

flight tube, and the peptide mass fingerprinting (PMF) was obtained.

PMF was interpreted and quantified by FlexAnalysis software 2.0 (Bruker Corporation, Ettlinger, Germany) following internal calibration with the trypsin autolysis products $[842.51(\mathrm{M}+\mathrm{H})$ and $2211.11(\mathrm{M}+\mathrm{H})]$. The data were mapped to corresponding proteins by searching against the SWISS-PROT (26) and National Center for Biotechnology Information databases (27) using the MASCOT search engine (www.matrixscience.com). Up to one missed cleavage was allowed for each peptide. Fixed modification was carbamidomethyl. Variable modification was oxidation. The max peptide tolerance was $\pm 200 \mathrm{ppm}$. $\mathrm{MH}^{+}$and monoisotopic were selected for mass values. Protein scores $>66$ were deemed significant $(\mathrm{P}<0.05)$.

Western blot analysis. Cells were lysed using radioimmunoprecipitation assay buffer containing $50 \mathrm{mM}$ Tris- $\mathrm{HCl}$, pH 8.0, $150 \mathrm{mM} \mathrm{NaCl}, 1 \%$ Triton $\mathrm{X}-100,0.5 \%$ SDS, $0.5 \%$ sodium deoxycholate, $1 \mathrm{mM}$ PMSF and $1 \mathrm{X}$ protease inhibitor cocktail (S8830; Sigma-Aldrich; Merck KGaA) at $4^{\circ} \mathrm{C}$ for $30 \mathrm{~min}$. Subsequently, the lysate was centrifuged at $12,000 \mathrm{x} \mathrm{g}$ for $15 \mathrm{~min}$ at $4^{\circ} \mathrm{C}$. The Bradford assay was used to determine protein concentrations and, subsequently, the proteins $(20 \mu \mathrm{g})$ were separated using 12\% SDS-PAGE, and transferred onto a polyvinylidene difluoride (PVDF) membrane. The membrane was then blocked in $1 \mathrm{XTBS}$ containing $5 \%$ non-fat milk at room temperature for $1 \mathrm{~h}$. The PVDF membrane was then incubated with primary antibodies against $14-3-3 \varepsilon$ (cat. no. 11648-2-AP;
ProteinTech Group, Inc., Chicago, IL, USA; cat. no. sc-393177; Santa Cruz Biotechnology, Inc., Dallas, TX, USA) or $\beta$-actin (cat. no. 60008-1-Ig; ProteinTech Group, Inc.) at a dilution of 1:1,000 in 1X TBST (20 mM Tris-HCl, pH 7.4, $150 \mathrm{mM} \mathrm{NaCl}$, $0.2 \%$ Tween 20 ) at $4^{\circ} \mathrm{C}$ overnight. Following washing with $1 \mathrm{X}$ TBST 3 times ( 7 min per wash), the membrane was incubated with horseradish peroxidase (HRP)-conjugated goat anti-rabbit IgG (cat. no. Pierce-31460; Thermo Fisher Scientific Inc.) or HRP-conjugated goat anti-mouse IgG (Pierce-31430; Thermo Fisher Scientific Inc.; diluted in 1X TBST at a dilution of 1:5,000) at room temperature for $1 \mathrm{~h}$. The signals were detected using WesternBright ${ }^{\mathrm{TM}}$ enhanced chemiluminescence kit (cat. no. K-12045-D50; Advansta, Inc, Menlo Park, CA, USA). The results were analyzed using Quantity One software (version 4.6.2, Bio-Rad Laboratories, Inc.).

Selective extraction of nuclear matrix intermediate fiber system and sample preparation. MG-63 cells were seeded on a $6-\mathrm{cm}$ culture dish with a $13-\mathrm{mm}$ coverslip in it. For the control group, $\sim 4 \times 10^{3}$ cells were seeded. For the curcumin-treated group, $\sim 1 \times 10^{4}$ cells were seeded, as cell growth was suppressed and certain cells died or detached during curcumin treatment. Following treatment for $36 \mathrm{~h}$, coverslips with seeded MG-63 cells were washed twice with warm PBS $\left(37^{\circ} \mathrm{C}\right)$. Subsequently, the cells were selectively extracted as previously described (28). Following selective extraction, the samples were fixed in $4 \%$ paraformaldehyde at $4^{\circ} \mathrm{C}$ for $20 \mathrm{~min}$. For observation using light microscopy, samples were stained with Coomassie brilliant blue at room temperature for $30 \mathrm{~min}$, 


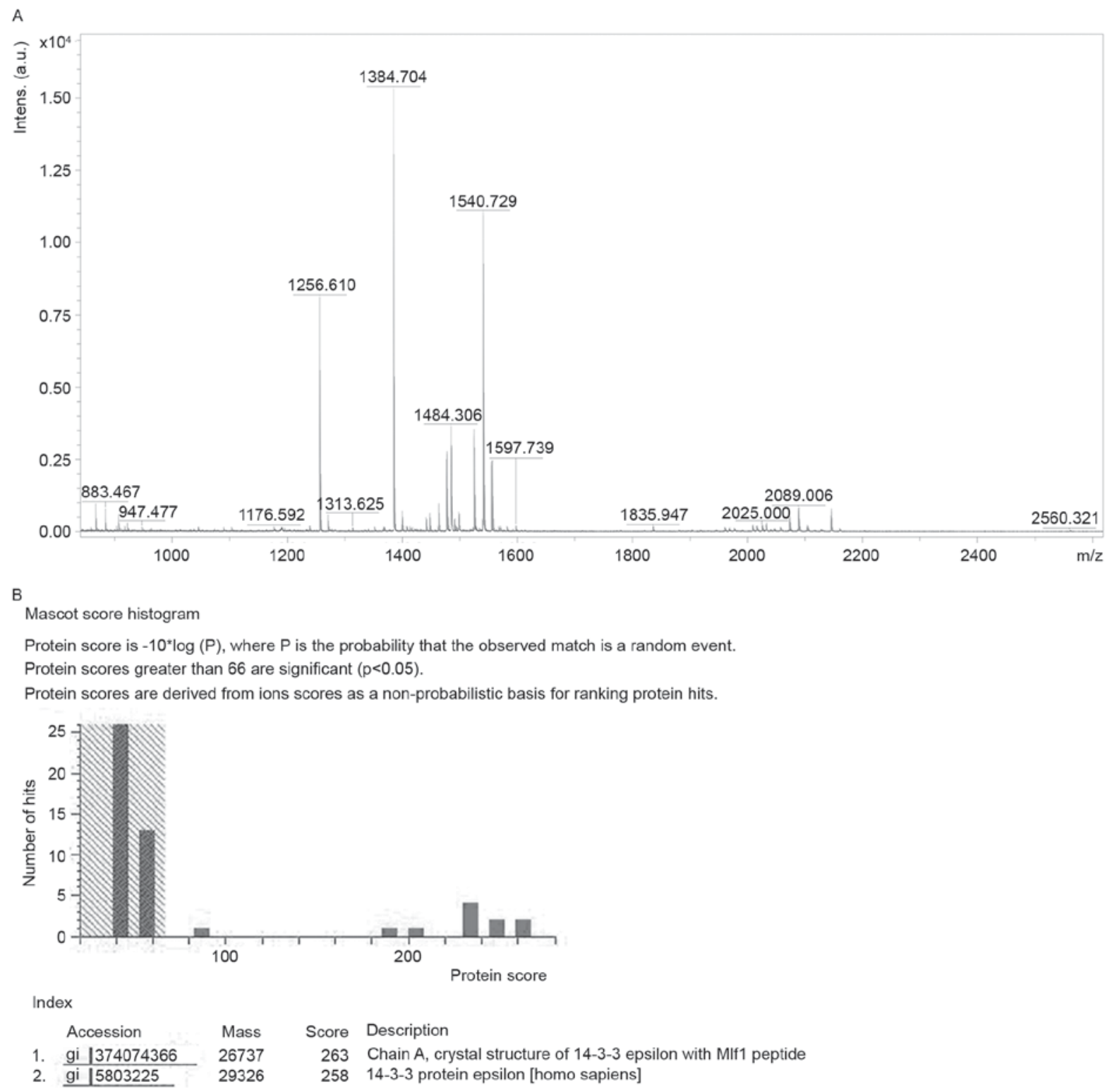

Figure 2. Identification of 14-3-3ع. (A) Peptide mass fingerprinting of spot 36. (B) MASCOT search results of spot 36. Spot 36 demonstrated a protein score of 258 , which was substantially higher than the threshold of 66, for identification as 14-3-3e. Intens (a.u.), intensity (arbitrary units).

followed by washing with double-distilled water several times. The samples were then observed by light microscopy under x400 magnification. For observation using fluorescence microscopy, samples were subjected to immunofluorescent staining as subsequently described.

Immunofluorescent staining (IF). MG-63 cells were seeded on a 6-well culture plate with a 13-mm coverslip in each well. For the control group, $\sim 2 \times 10^{3}$ cells were seeded. For the curcumin treated group, $\sim 5 \times 10^{3}$ cells were seeded. Cells seeded on coverslips were rinsed in warm PBS three times, permeabilized in PBS (containing $0.5 \%$ Triton $\mathrm{X}-100$ ) at $4^{\circ} \mathrm{C}$ for $20 \mathrm{~min}$ and fixed in $4 \%$ paraformaldehyde at $4^{\circ} \mathrm{C}$ for $10 \mathrm{~min}$. After $1 \mathrm{~h}$ of blocking in $5 \%$ bovine serum album (A8020; Beijing Solarbio Science \& Technology Co., Ltd., Beijing, China) at room temperature, cells were incubated with specific primary antibodies at room temperature for $30 \mathrm{~min}$ and then at $4^{\circ} \mathrm{C}$ for overnight. The primary antibodies were as follows: Rabbit anti-14-3-3e (1:50) (cat. no. 11648-2-AP; ProteinTech Group, Inc., Chicago, IL, USA)/mouse anti-Bcl-2-associated X protein (Bax; 1:100; cat. no. 60267-1-Ig; ProteinTech Group, Inc.), rabbit anti-14-3-3ع (1:50)/mouse anti-B-cell lymphoma 2 (Bcl-2; 1:100; cat. no. 60178-1-Ig; ProteinTech Group, Inc.), rabbit anti-14-3-3ع (1:50)/mouse anti-P53 (1:100; cat. no. 60283-1-Ig; ProteinTech Group, Inc.), muse anti-14-3-3e (1:50; cat. no. sc-393177; Santa Cruz Biotechnology, Inc.)/rabbit anti-c-Fos (1:50; cat. no. 26192-1-AP; ProteinTech Group, Inc.), mouse anti-14-3-3e (1:50)/rabbit anti-retinoblastoma (RB; 1:50; cat. no. 25628-1-AP; ProteinTech Group, Inc.). Following 3 washes (5 min per wash) at room temperature with PBS, cells were incubated with secondary antibodies mixture containing goat anti-mouse IgG labeled with fluorescein isothiocyanate (1:200; FITC; cat. no. P0196; Beyotime Institute of Biotechnology, Haimen, China) and goat anti-rabbit IgG labeled with cyanine (Cy)3 (1:200; cat. no. P0183; Beyotime Institute of Biotechnology) at room temperature for $3 \mathrm{~h}$. Hoechst 33258 
Table I. Identification of $14-3-3 \varepsilon$

\begin{tabular}{lc}
\hline Parameter & Value \\
\hline Spot no. & 36 \\
Identified protein & $14-3-3 \varepsilon$ \\
Gene symbol & YWHAE \\
NCBI accession number & NP_006752 \\
Mass, Da & 29,326 \\
pI & 4.63 \\
Coverage, \% & 47 \\
Matching peptides & 16
\end{tabular}

(cat. no. C1017; Beyotime Institute of Biotechnology) was used to stain the nucleus at room temperature for $5 \mathrm{~min}$. Following 3 washes ( $5 \mathrm{~min} /$ wash) at room temperature with PBS, the slides were then mounted with antifade mounting medium (cat. no. P0126; Beyotime Institute of Biotechnology), sealed at the edges with nail enamel and naturally dried at room temperature for $1 \mathrm{~h}$. The whole process was performed in darkness. The prepared samples were preserved in a light-tight box at $-20^{\circ} \mathrm{C}$ prior to observation. Samples were observed by laser scanning confocal microscope (LSCM; Olympus FV1000; Tokyo, Japan). Images were captured under x400 or x600 magnification.

Hematoxylin and eosin staining (HE). Cells seeded on coverslips were fixed in $95 \%$ ethanol (pre-cooling) at $4^{\circ} \mathrm{C}$ for $20 \mathrm{~min}$. All steps below were then performed at room temperature. Following washing with tap water for $40 \mathrm{sec}$, the coverslips were dipped into hematoxylin solution containing $0.5 \%(\mathrm{~m} / \mathrm{v})$ hematoxylin, $5 \%$ ethanol, $10 \%(\mathrm{~m} / \mathrm{v}) \mathrm{KAl}\left(\mathrm{SO}_{4}\right)_{2}, 0.25 \%(\mathrm{~m} / \mathrm{v})$ $\mathrm{HgO}$ for $5 \mathrm{~min}$, washed with tap water for $5 \mathrm{sec}$, differentiated in $75 \%$ ethanol containing $0.5 \% \mathrm{HCl}$ for $5-10 \mathrm{sec}$, and then washed with tap water again for $15 \mathrm{~min}$. The coverslips were then stained with eosin Y solution containing $0.5 \%(\mathrm{~m} / \mathrm{v})$ eosin $\mathrm{Y}$ and $20 \%$ ethanol for $1 \mathrm{~min}$, followed by dehydrating with two changes of $95 \%$ ethanol and two changes of $100 \%$ ethanol for 5 min each. Samples were then cleared with two changes of xylene for $5 \mathrm{~min}$ each, and mounted with neutral balsam. Once the mounting medium dried, samples were observed under a light microscope. Images were captured under x400 magnification.

Statistical analysis. Data reported in the graphs represent the averages of three independent experiments, and are presented as the mean \pm standard deviation. Data were analyzed by GraphPad Prism 6 software (GraphPad Software, Inc., La Jolla, CA, USA) using two-way analysis of variance followed by Tukeys multiple comparison test.

\section{Results}

Differentially expressed NMPs were identified using $2 \mathrm{D}$ gel electrophoresis. In order to systematically analyze the alteration in the protein expression profile in the nuclear matrix during curcumin-induced apoptosis, selectively extracted
NMPs were separated using 2D gel electrophoresis. The concentrations of protein spots were analyzed using PDQuest 8.0 software. Protein spots with a fold change $>2$ were subjected to MALDI-TOF-MS analysis (Fig. 1A). The protein spot 36 was identified as protein 14-3-3e. As presented in Fig. 1B and $\mathrm{C}$, the quantity of spot 36 was decreased markedly following treatment with curcumin, compared with the control group. The identification is presented in Fig. 2 and Table I. Protein score was 258 (a score $\geq 66$ indicates successful identification).

Expression of 14-3-3E is downregulated following curcumin treatment. To determine whether curcumin may regulate the expression of 14-3-3e, western blot analysis was performed to detect the expression level of 14-3-3e. As presented in Fig. 3, following treatment with curcumin for $24 \mathrm{~h}$, the expression level of $14-3-3 \varepsilon$ was significantly decreased in MG-63 cells $(\mathrm{P}<0.001)$, as compared with that in control cells. Notably, a truncated fragment was identified with the downregulation of $14-3-3 \varepsilon$. To validate whether the detected fragment was the $14-3-3 \varepsilon$ protein, a rabbit antibody (Fig. 3A) and a mouse monoclonal antibody (Fig. 3B) were used for an immunoblot assay, and the truncated fragment was detected using the two antibodies. Thus, it was deduced that this fragment was a specific short term of $14-3-3 \varepsilon$ (14-3-3e-S).

Fluorescence intensity of 14-3-3e in the nuclear matrix of apoptotic cells is decreased following treatment with curcumin. Commonly, the cellular localization of proteins decides their functions (29-31). Using immunofluorescence labeling technology enabled the identified of the localization of 14-3-3e in MG-63 cells and the nuclear matrix-intermediate filament system, prior to and following curcumin-induced apoptosis. As presented in Fig. 4A, MG-63 cells exhibited irregular morphology, the majority of which were long spindle- or multiple angle-shaped with sheet or horn-like processes on the cell surface, and large off-center nuclei. Results from the immunofluorescence assay (Fig. 4B) demonstrated that $14-3-3 \varepsilon$ was distributed evenly throughout MG-63 cells. Following treatment with curcumin, the cells shrunk and became round in shape, and the connections between cells and the processes on the cell surface disappeared. Nucleus staining revealed karyopyknosis and more intense staining, as compared with the control cells (Fig. 4A). Fluorescence microscopy demonstrated that the fluorescence intensity in the nucleus was weaker (Fig. 4B), compared with that in the cytoplasm, indicating a decreased level of $14-3-3 \varepsilon$ in the nucleus.

As presented Fig. 4C, the nuclear matrix-intermediate filament (NM-IF) system in MG-63 cells underwent significant alteration during curcumin-induced apoptosis. Nuclear matrix connected with intermediate filaments through the nuclear lamina to form an integrated system. In cells of the control group, intermediate filament was extended between the edge of the nuclear lamina and the periphery of the cell to form an intact network structure. In addition, the filaments were arranged regularly, and gradually became sparse from the perinuclear region to the edge of the cell. The nuclear lamina was thick and intensely stained. Fiber hierarchy of nuclear matrix was compact with deep staining. Following treatment with curcumin, the nuclear matrix-intermediate filament system tended to be fractured, disordered and lightly stained. 
A
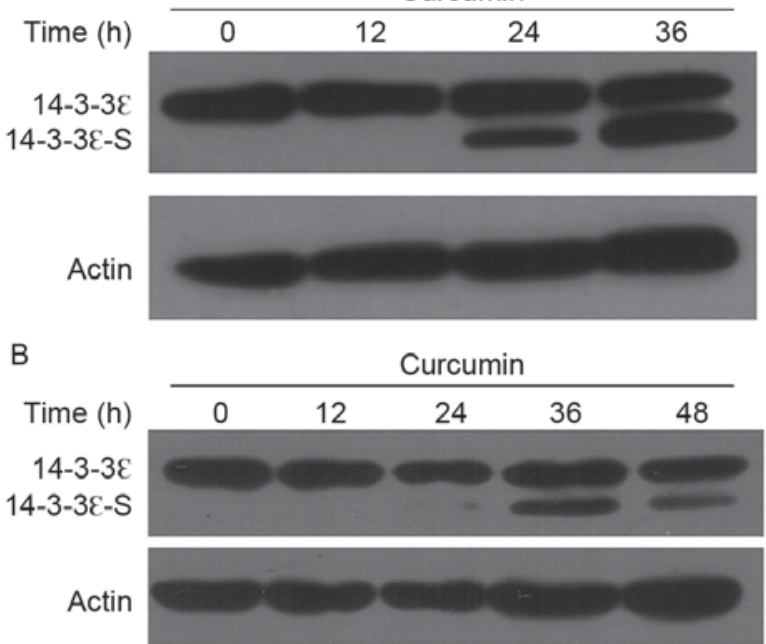

C

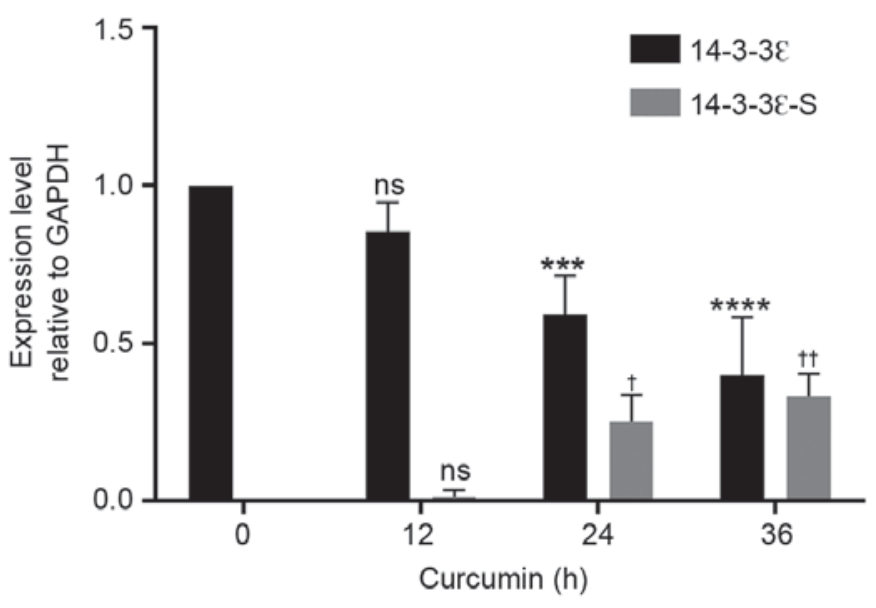

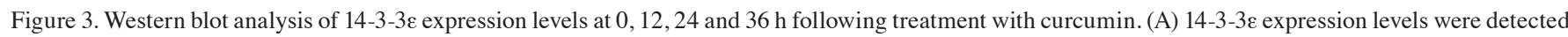

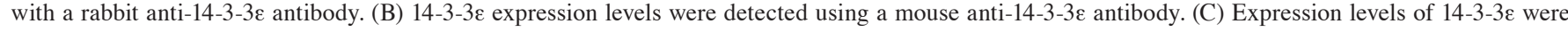
quantified using Quantity One software. Expression levels relative to GAPDH were normalized to the 14-3-3 $\varepsilon$ level at $0 \mathrm{~h}$ and analyzed using two-way analysis of variance ( $\mathrm{n}=3$, mean \pm standard error). ${ }^{* * *} \mathrm{P}<0.001$ and ${ }^{* * * * *} \mathrm{P}<0.0001$ vs. $14-3-3 \varepsilon,{ }^{\dagger} \mathrm{P}<0.05$ and ${ }^{\dagger \dagger} \mathrm{P}<0.01$ vs. $14-3-3 \varepsilon-\mathrm{S}$ at 0 h. ns, no significance; $14-3-3 \varepsilon-\mathrm{S}$, truncated specific short term of $14-3-3 \varepsilon ;{ }^{*}$ for $14-3-3 \varepsilon$ and $\dagger$ for $14-3-3 \varepsilon-S$.
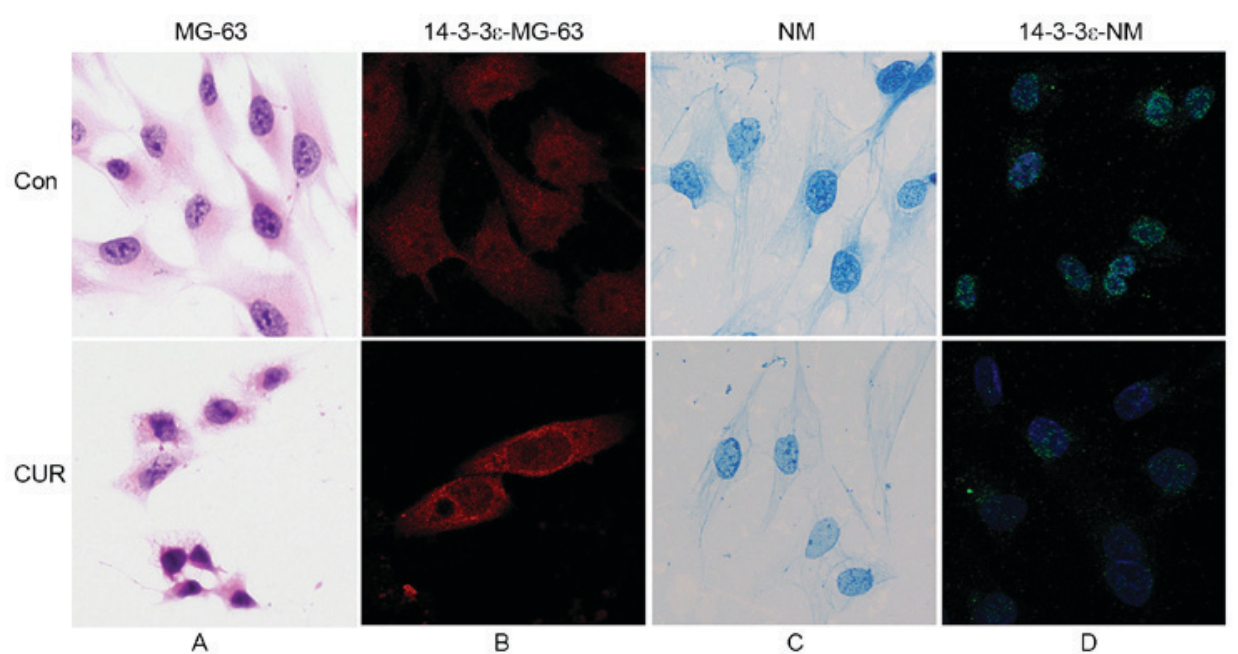

Figure 4. Localization of 14-3-3e in MG-63 cells and NM. (A) HE staining of MG-63 cells. (B) IF. The red fluorescence presented localization of 14-3-3e in whole MG-63 cells. (C) Coomassie brilliant blue staining of the NM-IF system. (D) IF. The green fluorescence demonstrated localization of 14-3-3 $\varepsilon$ on NM-IF. The blue fluorescence presented the nucleus. NM, nuclear matrix; IF, intermediate filament; HE, hematoxylin and eosin; Con, control; CUR, curcumin-treated.

The intermediate fiber was sparse and discontinuous. The nuclear lamina was thin and the fiber hierarchy of the nuclear matrix was sparse. The cytoskeleton was no longer intact. Immunofluorescence staining results (Fig. 4D) revealed that the fluorescence intensity of $14-3-3 \varepsilon$ in the nuclear matrix of apoptotic cells was decreased, compared with that in normal cells.

Apoptosis-associated proteins are co-localized with 14-3-3ع in MG-63 cells. The expression level and localization of $14-3-3 \varepsilon$ in MG-63 cells were significantly altered following treatment with curcumin. To validate that $14-3-3 \varepsilon$ was associated with apoptosis, a confocal laser-scanning double immunofluorescence staining method was used to observe the localization association between $14-3-3 \varepsilon$ and apoptosis-associated proteins, including Bcl-2, Bax, p53, RB and c-FOS. In Fig. 5A-C, 14-3-3e was labeled with red fluorescent dye $\mathrm{Cy} 3$, whereas Bax, Bcl-2 and p53 were labeled with green fluorescent FITC. In Fig. 5D and E, 14-3-3e was labeled with FITC, and RB and c-FOS protein were labeled with $\mathrm{Cy} 3$. Orange fluorescence indicated a co-localization association between two proteins. The results of the present study demonstrated that $14-3-3 \varepsilon$ was primarily distributed in the cytoplasm with a centralized distribution in the area adjacent to the nucleus. The distribution of the protein in the nucleus was decreased relative to that in the cytoplasm. Following treatment with curcumin, $14-3-3 \varepsilon$ distribution remained primarily in the cytoplasm, but in the nucleus the distribution was weakened.

As presented in Fig. 5A-C, Bax, Bcl-2 and p53 were primarily distributed in the cytoplasm, and these proteins 


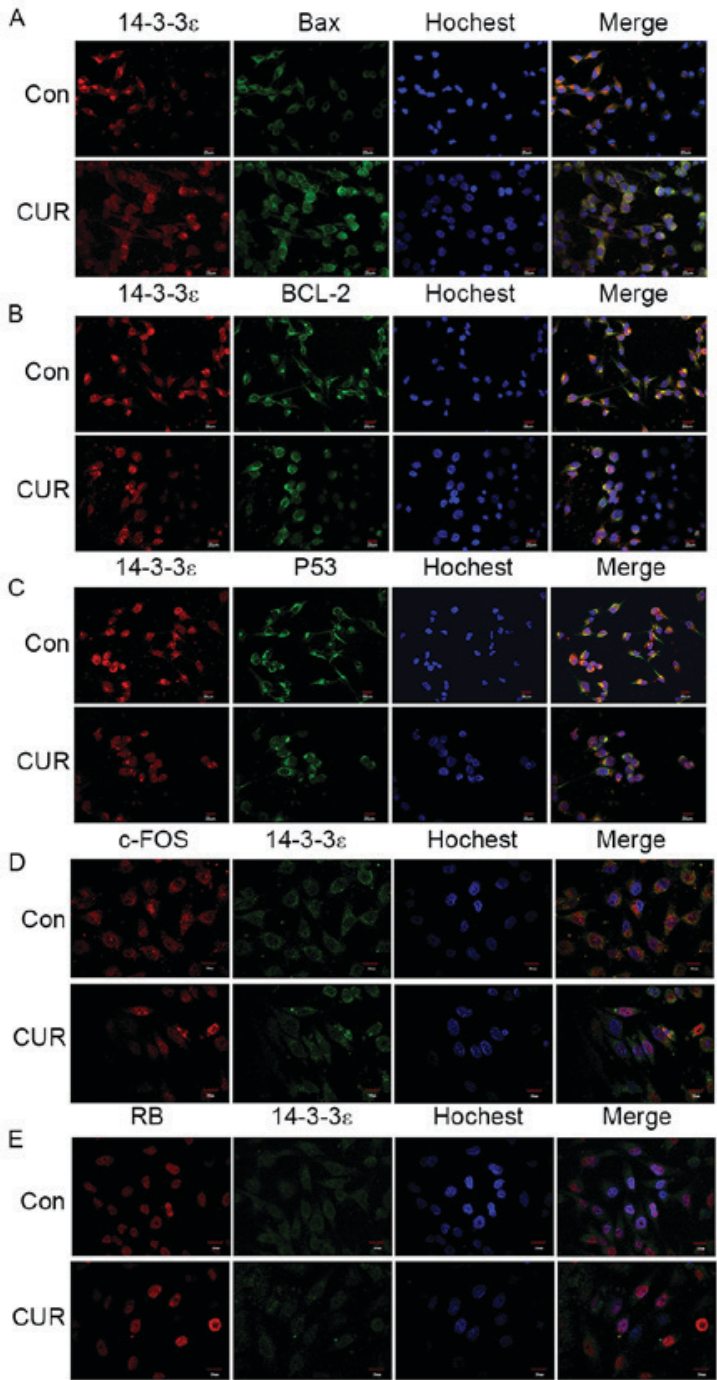

Figure 5. Laser-scanning confocal microscopy revealed the co-localization

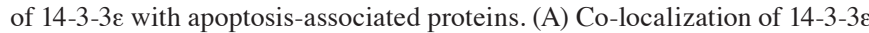
with Bax. (B) Co-localization of 14-3-3e with Bcl-2. (C) Co-localization of $14-3-3 \varepsilon$ with P53. Magnification, $x 400$, with $14-3-3 \varepsilon$ labeled with red Cy3 and Bax, Bcl-2 and p53 labeled with green FITC. (D) Co-localization of 14-3-3 $\varepsilon$ with c-FOS. (E) Co-localization of 14-3-3e with RB. Magnification, x600, with 14-3-3e labeled with green FITC and c-FOS and RB labeled with red $\mathrm{Cy} 3$. Bcl-2, B-cell lymphoma 2; Bax, Bcl-2-associated-X protein; RB, retinoblastoma; FITC, fluorescein isothiocyanate; $\mathrm{Cy}$, cyanine; Con, control; CUR, curcumin-treated.

were at low levels in the nucleus. Among these proteins, Bcl-2 revealed an intense fluorescent stain in a concentrated area. The results from the merged images demonstrated orange fluorescence in the cytoplasm for the three proteins, indicating that $14-3-3 \varepsilon$ was co-localized with Bax, Bcl-2 and p53 in the cytoplasm. Following treatment with curcumin, Bax and Bcl-2 remained in the cytoplasm, the fluorescence intensity of Bax was increased compared with that in control cells and the concentrated distribution of $\mathrm{Bcl}-2$ fluorescence was no longer visible. The distribution of p53 remained primarily in the cytoplasm, but there was an increase of fluorescence in the nucleus, as compared with that in control cells. No orange fluorescence was observed in the merged images, which indicated that co-localization of $14-3-3 \varepsilon$ with $\mathrm{Bax}, \mathrm{Bcl}-2$ and $\mathrm{p} 53$ was decreased or non-existent following curcumin treatment.
The co-localization association between 14-3-3e and c-FOS and $\mathrm{RB}$ is presented in Fig. 5D and E. c-FOS was primarily distributed in the cytoplasm, with a limited amount in the nucleus. RB was restricted to the nucleus, with the exception of the nucleolus. The superimposition demonstrated that 14-3-3e was co-localized with c-FOS in the cytoplasm. However, for $\mathrm{RB}$, there was no apparent co-localization association between $14-3-3 \varepsilon$ and RB. Compared with the control group, after treatment with curcumin, the fluorescence intensity of c-FOS was identified to be significantly decreased in the cytoplasm, but in the nucleus the fluorescence intensity of c-FOS was increased. The fluorescence intensity of RB was increased with no localization alteration. The superimposition demonstrated that there was no co-localization between $14-3-3 \varepsilon$ and RB, and the co-localization association between $14-3-3 \varepsilon$ and c-FOS was significantly weakened.

\section{Discussion}

NMPs are involved with a number of different activities in the nucleus including DNA replication and synthesis, RNA transcription and processing, and gene expression regulation; thus, NMPs serve an important function in cells (22). Identifying the nuclear localization of $14-3-3 \varepsilon$ may demonstrate that it exhibits a novel regulatory role in MG-63 cells. In the present study, $14-3-3 \varepsilon$ was identified to be a nuclear matrix-associated protein using 2D gel electrophoresis. In addition, western blot analysis validated the existence of $14-3-3 \varepsilon$ in the nuclear matrix, and the expression and localization of $14-3-3 \varepsilon$ in the nuclear matrix was observed using immunofluorescent labeling. Liu et al (7) identified that $14-3-3 \varepsilon$ was primarily located in the nucleus of SW480 colon cancer cells, with a perinuclear translocation induced by triptolide. There are a limited number of studies which have focused on the localization of $14-3-3 \varepsilon$. Our early studies focusing on apoptosis of MG-63 cells had identified that important functional proteins including nucleophosmin, prohibitin and heterogeneous nuclear ribonucleoprotein (hnRNP) A2/B1 were located in the nuclear matrix (32). By associating with the nuclear matrix, nucleophosmin, prohibitin and hnRNP A2/B1 served functions in regulating cell carcinogenesis and apoptosis (32). Thus, the localization of $14-3-3 \varepsilon$ in the nuclear matrix indicated that it served an unknown function in the regulation of cell processes, which required further study.

Expression levels of important functional proteins are typically altered during cell apoptosis (33-35). The results of the present study, using 2D analysis, revealed a significant decrease of $14-3-3 \varepsilon$ in the nuclear matrix of apoptotic MG-63 cells. This alteration indicated that $14-3-3 \varepsilon$, as an important nuclear matrix-associated protein, was associated with the regulation of apoptosis in MG-63 cells. In addition, western blot analysis demonstrated that the expression level of 14-3-3e was decreased following curcumin treatment, in a time-dependent manner. However, the expression level of 14-3-3e-S demonstrated an opposite trend, as this increased with treatment duration. Results from immunofluorescence assays demonstrated a decrease in fluorescence intensity of $14-3-3 \varepsilon$ in the nuclear matrix of apoptotic cells. Therefore, the results of the present study demonstrated a decrease in the expression level of $14-3-3 \varepsilon$. Nagappan et al (5) validated that 
downregulation of $14-3-3 \varepsilon$ induced apoptosis in AGS gastric cancer cells. Consistently, a study by Wu et al (36) revealed that rosiglitazone-induced upregulation of $14-3-3 \varepsilon$ decreased the apoptosis of neuronal cells. These studies indicated that the downregulation of $14-3-3 \varepsilon$ was an upstream event of apoptosis, rather than a downstream one. Notably, the results of the present study revealed that the expression level of $14-3-3 \varepsilon-S$ was increased along with apoptosis, which should be additionally investigated.

The regulation of cell apoptosis is a complex process (37). Thus, we hypothesized that the interactions between 14-3-3e and a number of additional apoptosis-associated proteins may be involved in cell apoptosis. Using LSCM, it was observed in the present study that $14-3-3 \varepsilon$ was co-localized with Bax, Bcl-2, p53 and c-FOS in the cytoplasm of MG-63 cells. Following treatment with curcumin, their co-localization was decreased. To the best of our knowledge, only Bcl-2-associated death promoter has been identified to bind to $14-3-3 \varepsilon$, resulting in its retention in the cytoplasm and suppression of apoptosis (38). Our group hypothesized that Bax may bind to $14-3-3 \varepsilon$, thus impairing its pro-apoptotic ability. Previous studies have demonstrated that 14-3-3o, $\tau$, $\zeta$ and $\varepsilon$ may bind to Bax $(18,39)$, but the interaction between $14-3-3 \varepsilon$ and Bax requires validation. The ratio between Bax and Bcl-2 is a key factor to determine whether apoptosis occurs or not (40). The results of the present study demonstrated that $14-3-3 \varepsilon$ was co-localized with Bax and Bcl-2, which indicated that $14-3-3 \varepsilon$ may regulate the progress of apoptosis by influencing the ratio between Bax and Bcl-2 . As an important transcription factor, p53 may regulate the expression of multiple pro-apoptotic genes including Bax and Fas, thereby serving a pro-apoptotic function $(41,42)$. Gbormittah et al (43) demonstrated a co-expression and co-localization association between $14-3-3 \varepsilon$ and p53, using chromosome gene mapping. To the best of our knowledge, there are no other studies which demonstrated an association between $14-3-3 \varepsilon$ and $\mathrm{p} 53$. In the present study, $14-3-3 \varepsilon$ was identified to be co-localized with p53 in the cytoplasm in MG-63 cells, which indicated that the interaction between 14-3-3e and p53 may serve a function in the apoptosis of MG-63 cells. c-FOS is a proto-oncogene which has been identified to be associated with the occurrence, invasion and metastasis of multiple types of tumor (44). In some studies, c-FOS was identified to be involved with the death of nerve cells (45-47). In addition, 14-3-3e has been demonstrated to serve a function in the death of nerve cells (48-50). Although, to the best of our knowledge, no studies have identified an association between $14-3-3 \varepsilon$ and c-FOS, their co-localization suggests that these two may interact. Co-localization of 14-3-3e with the aforementioned apoptosis-associated proteins indicated that $14-3-3 \varepsilon$ may participate in the regulation of apoptosis of MG-63 cells.

The present study demonstrated that $14-3-3 \varepsilon$ exists in the nuclear matrix of MG-63 cells and is downregulated during curcumin-induced apoptosis. Furthermore, $14-3-3 \varepsilon$ is co-localized with Bax, Bcl-2, p53 and c-FOS in the cytoplasm of MG-63 cells, and these co-localizations are decreased following curcumin treatment. These results indicated that $14-3-3 \varepsilon$ is a nuclear matrix-associated protein and it may serve a role in the regulatory events of apoptosis.

\section{Acknowledgements}

The present study was supported by the National Natural Science Foundation of China (grant nos. 81272921, 81272245, 81272445,81471970 and 81670542), Joint Programme by Healthy Care System and Educational Department in Fujian Province (grant no. WKJ-FJ-16), The Natural Science Foundation of Fujian Province of China (grant no. 2013D004) and the Fundamental Research Funds for the Central Universities (grant no. 20720140545).

\section{References}

1. Morrison DK: The 14-3-3 proteins: Integrators of diverse signaling cues that impact cell fate and cancer development. Trends Cell Biol 19: 16-23, 2009.

2. van Hemert MJ, Steensma HY and van Heusden GP: 14-3-3 proteins: Key regulators of cell division, signalling and apoptosis. Bioessays 23: 936-946, 2001

3. Kosaka Y, Cieslik KA, Li L, Lezin G, Maguire CT, Saijoh Y, Toyo-oka K, Gambello MJ, Vatta M, Wynshaw-Boris A, et al: $14-3-3 \varepsilon$ plays a role in cardiac ventricular compaction by regulating the cardiomyocyte cell cycle. Mol Cell Biol 32: 5089-5102, 2012.

4. Cui C, Ren X, Liu D, Deng X, Qin X, Zhao X, Wang E and Yu B: 14-3-3 epsilon prevents G2/M transition of fertilized mouse eggs by binding with CDC25B. BMC Dev Biol 14: 33, 2014.

5. Nagappan A, Park HS, Park KI, Hong GE, Yumnam S, Lee HJ, Kim MK, Kim EH, Lee WS, Lee WJ, et al: Helicobacter pylori infection combined with DENA revealed altered expression of p53 and 14-3-3 isoforms in Gulo-/- mice. Chem Biol Interact 206: 143-152, 2013.

6. Zhong J, Kong X, Zhang H, Yu C, Xu Y, Kang J, Yu H, Yi H, Yang X and Sun L: Inhibition of CLIC4 enhances autophagy and triggers mitochondrial and ER stress-induced apoptosis in human glioma U251 cells under starvation. PLoS One 7: e39378, 2012.

7. Liu Y, Song F, Wu WK, He M, Zhao L, Sun X, Li H, Jiang Y, Yang Y and Peng K: Triptolide inhibits colon cancer cell proliferation and induces cleavage and translocation of 14-3-3 epsilon. Cell Biochem Funct 30: 271-278, 2012.

8. Fong WH, Tsai HD, Chen YC, Wu JS and Lin TN: Anti-apoptotic actions of PPAR-gamma against ischemic stroke. Mol Neurobiol 41: 180-186, 2010.

9. Wang X, Grammatikakis N, Siganou A and Calderwood SK: Regulation of molecular chaperone gene transcription involves the serine phosphorylation, 14-3-3 epsilon binding, and cytoplasmic sequestration of heat shock factor 1. Mol Cell Biol 23: 6013-6026, 2003.

10. Leal MF, Calcagno DQ, Demachki S, Assumpcão PP, Chammas R, Burbano RR and Smith Mde A: Clinical implication of 14-3-3 epsilon expression in gastric cancer. World $\mathrm{J}$ Gastroenterol 18: 1531-1537, 2012.

11. Ruiz Esparza-Garrido R, Velázquez-Flores MÁ, Diegopérez-Ramirez J, López-Aguilar E, Siordia-Reyes G, Hernández-Ortiz M, Martinez-Batallar AG Encarnación-Guevara S, Salamanca-Gómez F and Arenas-Aranda DJ: A proteomic approach of pediatric astrocytomas: MiRNAs and network insight. J Proteomics 94: $162-175,2013$.

12. Ko BS, Jan YJ, Chang TC, Liang SM, Chen SC, Liu TA, Wu YM, Wang $J$ and Liou JY: Upregulation of focal adhesion kinase by $14-3-3 \varepsilon$ via $N F \kappa B$ activation in hepatocellular carcinoma. Anticancer Agents Med Chem 13: 555-562, 2013.

13. Ko BS, Chang TC, Hsu C, Chen YC, Shen TL, Chen SC, Wang J, Wu KK, Jan YJ and Liou JY: Overexpression of 14-3-3e predicts tumour metastasis and poor survival in hepatocellular carcinoma. Histopathology 58: 705-711,2011.

14. Liang S, Xu Y, Shen G, Liu Q, Zhao X, Xu Z, Xie X, Gong F, Li R and Wei Y: Quantitative protein expression profiling of 14-3-3 isoforms in human renal carcinoma shows 14-3-3 epsilon is involved in limitedly increasing renal cell proliferation. Electrophoresis 30: 4152-4162, 2009.

15. Cimino D, Fuso L, Sfiligoi C, Biglia N, Ponzone R, Maggiorotto F, Russo G, Cicatiello L, Weisz A, Taverna D, et al: Identification of new genes associated with breast cancer progression by gene expression analysis of predefined sets of neoplastic tissues. Int $\mathrm{J}$ Cancer 123: 1327-1338, 2008. 
16. Porter GW, Khuri FR and Fu H: Dynamic 14-3-3/client protein interactions integrate survival and apoptotic pathways. Semin Cancer Biol 16: 193-202, 2006.

17. Zha J, Harada H, Yang E, Jockel J and Korsmeyer SJ: Serine phosphorylation of death agonist BAD in response to survival factor results in binding to 14-3-3 not BCL-X(L). Cell 87: 619-628, 1996

18. Nomura M, Shimizu S, Sugiyama T, Narita M, Ito T, Matsuda H and Tsujimoto Y: 14-3-3 Interacts directly with and negatively regulates pro-apoptotic Bax. J Biol Chem 278: 2058-2065, 2003.

19. Zhang L, Chen J and Fu H: Suppression of apoptosis signal-regulating kinase 1-induced cell death by 14-3-3 proteins. Proc Nat Acad Sci USA 96: 8511-8515, 1999.

20. Brunet A, Kanai F, Stehn J, Xu J, Sarbassova D, Frangioni JV, Dalal SN, DeCaprio JA, Greenberg ME and Yaffe MB: 14-3-3 transits to the nucleus and participates in dynamic nucleocytoplasmic transport. J Cell Biol 156: 817-828, 2002.

21. Fey EG, Wan KM and Penman S: Epithelial cytoskeletal framework and nuclear matrix-intermediate filament scaffold Three-dimensional organization and protein composition. J Cell Biol 98: 1973-1984, 1984

22. Gerner C, Seelos C and Sauermann G: Alteration of nuclear matrix protein composition during apoptosis in rat embryo cells. Exp Cell Res 238: 472-480, 1998.

23. Michishita E, Kurahashi T, Suzuki T, Fukuda M, Fujii M, Hirano $\mathrm{H}$ and Ayusawa D: Changes in nuclear matrix proteins during the senescence-like phenomenon induced by 5 -chlorodeoxyuridine in HeLa cells. Exp Gerontol 37: 885-890, 2002.

24. Jing GJ, Xu DH, Shi SL, Li QF, Wang SY, Wu FY and Kong HY: Aberrant expression of nuclear matrix proteins during HMBA-induced differentiation of gastric cancer cells. World J Gastroenterol 16: 2176-2182, 2010.

25. Shevchenko A, Wilm M, Vorm O and Mann M: Mass spectrometric sequencing of proteins silver-stained polyacrylamide gels Anal Chem 68: 850-858, 1996

26. Boutet E, Lieberherr D, Tognolli M, Schneider M, Bansal P, Bridge AJ, Poux S, Bougueleret L and Xenarios I: UniProtKB/Swiss-Prot, the manually annotated section of the UniProt KnowledgeBase: How to use the entry view. Methods Mol Biol 1374: 23-54, 2016.

27. NCBI Resource Coordinators: Database resources of the national center for biotechnology information. Nucleic Acids Res 45: D12-D17, 2017.

28. Li QF: Effect of retinoic acid on the changes of nuclear matrix in termediate filament system in gastric carcinoma cells. World J Gastroenterol 5: 417-420, 1999.

29. Poüs C, Klipfel L and Baillet A: Cancer-related functions and subcellular localizations of septins. Front Cell Dev Biol 4: 126 2016.

30. Hsu YT, Wolter KG and Youle RJ: Cytosol-to-membrane redistribution of Bax and Bcl-X(L) during apoptosis. Proc Natl Acad Sci USA 94: 3668-3672, 1997.

31. Boonstra J and Verkleij AJ: Regulation of enzyme activity in vivo is determined by its cellular localization. Adv Enzyme Regul 44: 61-73, 2004.

32. Zhao ZL, Li QF, Zheng YB, Chen LY, Shi SL and Jing GJ: The aberrant expressions of nuclear matrix proteins during the apoptosis of human osteosarcoma cells. Anat Rec (Hoboken) 293 813-820, 2010

33. Bai Z, Ye Y, Liang B, Xu F, Zhang H, Zhang Y, Peng J, Shen D, Cui Z, Zhang $Z$ and Wang S: Proteomics-based identification of a group of apoptosis-related proteins and biomarkers in gastric cancer. Int J Oncol 38: 375-383, 2011.

34. Wyllie AH: Apoptosis (the 1992 Frank Rose Memorial Lecture). Br J Cancer 67: 205-208, 1993
35. Bazhanova ED, Sukhanov DS and Teplyi DL: Pathways of apoptosis regulation in hepatocytes induced by first-line antitubercular drugs. Bull Exp Biol Med 158: 650-653, 2015.

36. Wu JS, Cheung WM, Tsai YS, Chen YT, Fong WH, Tsai HD, Chen YC, Liou JY, Shyue SK, Chen JJ, et al: Ligand-activated peroxisome proliferator-activated receptor-gamma protects against ischemic cerebral infarction and neuronal apoptosis by 14-3-3 epsilon upregulation. Circulation 119: 1124-1134, 2009.

37. Wong RS: Apoptosis in cancer: From pathogenesis to treatment. J Exp Clin Cancer Res 30: 87, 2011.

38. Won J, Kim DY, La M, Kim D, Meadows GG and Joe CO: Cleavage of 14-3-3 protein by caspase-3 facilitates bad interaction with Bcl-x(L) during apoptosis. J Biol Chem 278: 19347-19351, 2003.

39. Samuel T, Weber HO, Rauch P, Verdoodt B, Eppel JT, McShea A, Hermeking $\mathrm{H}$ and Funk JO: The G2/M regulator 14-3-3sigma prevents apoptosis through sequestration of Bax. J Biol Chem 276: 45201-45206, 2001.

40. Selvakumaran M, Lin HK, Miyashita T, Wang HG, Krajewski S, Reed JC, Hoffman B and Liebermann D: Immediate early up-regulation of bax expression by p53 but not TGF beta 1: A paradigm for distinct apoptotic pathways. Oncogene 9: 1791-1798, 1994.

41. Meek DW: The p53 response to DNA damage. DNA Repair (Amst) 3: 1049-1056, 2004.

42. Fridman JS and Lowe SW: Control of apoptosis by p53. Oncogene 22: 9030-9040, 2003.

43. Gbormittah FO, Haab BB, Partyka K, Garcia-Ott C, Hancapie M and Hancock WS: Characterization of glycoproteins in pancreatic cyst fluid using a high-performance multiple lectin affinity chromatography platform. J Proteome Res 13: 289-299, 2014.

44. Milde-Langosch K: The Fos family of transcription factors and their role in tumourigenesis. Eur J Cancer 41: 2449-2461, 2005.

45. Smeyne RJ, Vendrell M, Hayward M, Baker SJ, Miao GG, Schilling K, Robertson LM, Curran T and Morgan JI: Continuous c-fos expression precedes programmed cell death in vivo. Nature 363: 166-169, 1993.

46. Chen X, Shen J, Wang Y, Chen X, Yu S, Shi H and Huo K: Up-regulation of c-Fos associated with neuronal apoptosis following intracerebral hemorrhage. Cell Mol Neurobiol 35: 363-376, 2015.

47. Yu AY, Su QR, Wang L, Zhou J and Liu XH: Effects of citalopram on the expression of PCNA and C-fos and cell apoptosis in rat frontal cortical neurons after stress. Zhongguo Ying Yong Sheng Li Xue Za Zhi 30: 439-442, 2014 (In Chinese).

48. Morales D, Skoulakis EC and Acevedo SF: 14-3-3s are potential biomarkers for HIV-related neurodegeneration. J Neurovirol 18: 341-353, 2012.

49. Gelman BB and Nguyen TP: Synaptic proteins linked to HIV-1 infection and immunoproteasome induction: Proteomic analysis of human synaptosomes. J Neuroimmune Pharmacol 5: 92-102, 2010.

50. Toyo-oka K, Shionoya A, Gambello MJ, Cardoso C, Leventer R, Ward HL, Ayala R, Tsai LH, Dobyns W, Ledbetter D, et al: 14-3-3epsilon is important for neuronal migration by binding to NUDEL: A molecular explanation for Miller-Dieker syndrome. Nat Genet 34: 274-285, 2003.

This work is licensed under a Creative Commons Attribution-NonCommercial-NoDerivatives 4.0 International (CC BY-NC-ND 4.0) License. 